\title{
Environmental economic model of risk management and costs in the framework of the quality management system
}

\author{
Victoria Borkovskaya ${ }^{1, *}$, Evgeniy Degaev ${ }^{1}$ and Irina Burkova ${ }^{2}$ \\ ${ }^{1}$ Moscow State University of Civil Engineering, Yaroslavskoe shosse, 26, Moscow, 129337, Russia \\ ${ }^{2}$ V.A. Trapeznikov Institute of Control Science of Russian Academy of Science, 65, Profsoyuznaya \\ str. Moscow, 117997, Russia
}

\begin{abstract}
The article considers the environmental economic model of risk management and the costs associated with them. In the field of eco-friendly construction and labor safety, it is customary to allocate occupational hazards and hazards, expressed by quantitative or qualitative parameters of occupational risk. Risk management or environmental risk means the recognition and analysis of risks, the development and implementation of management decisions to reduce the likelihood of adverse situations, as well as the possible reduction of material or other losses. Risk management helps to get out of the zone of uncertainty into a situation with more or less predictable results. The methodology for applying the environmental economic model under consideration is a cyclic order of performing interrelated practical actions known as the Deming-Shewhart cycle, which is inextricably linked to the process approach and the quality management system. Synthesis of the principles of the quality management system and mechanisms for managing environmental risks and costs ensures high adaptability to any external and internal stress situations, reveals professional risks in a timely manner, optimizes processes and, as a result, reduces costs.
\end{abstract}

\section{Introduction}

The effectiveness of the eco-friendly construction organization in many respects depends on the quality management system (QMS), which is aimed at achieving maximum quality of products and processes in the company. As a management system, the QMS affects all the organization's processes, including those related to finances. Therefore, when developing and implementing a QMS in an organization, it is first of all necessary to study the effective management of costs for quality and to calculate design risks. Economic criteria, such as costs and efficiency, should be used.

Presented in this paper is a model that addresses the topic of this special issue: Risk Analysis Validation and Trust in Environmental Risk Management. We do that by presenting a systems approach that links all four of those concepts [9]. The underlying logic: Validation

${ }^{*}$ Corresponding author: BorkovskayaVG@mgsu.ru 
should test how effectively a risk analysis supports actual, real-world implemented risk management. Our approach is based on a flowchart linking all of the elements from inputs through risk analysis, risk reporting and transparency, then how that reporting-transparency support the risk management decision making process and associated third party and stakeholder reviews (formal or informal), which in turn determine the trust and acceptance necessary for the real-world implementation of risk management actions.

We take that flowchart and identify within it sixteen critical elements. Then, we specify a validation test for each of those elements. Validation, then, consists of subjecting the risk analysis to those sixteen tests. Those tests, taken together, assess the effectiveness of the risk analysis for supporting implemented risk management. Another key feature: We divide the flowchart into an Analysts' Domain, a Users' Domain, and an Analysis Community Domain. The Analysts' Domain is where the risk analysts work; then, the Users' Domain stands between their work and implementation. The Analysis Community Domain is comprised of the communities of risk analysts and commissioners of risk analyses. Those two communities are where we would, as part of building our systems approach to risk analysis validation, build a "Culture of Analysis Quality," where the sixteen validation tests would be enforced by both of those communities [3-8, 14, 15, 19].

The effectiveness of the eco-friendly construction organization in many respects depends on the quality management system (QMS), which is aimed at achieving maximum quality of products and processes in the company. As a management system, the QMS affects all the organization's processes, including those related to finances. Therefore, when developing and implementing a QMS in an organization, it is first of all necessary to study the effective management of costs for quality and to calculate design risks. Economic criteria, such as costs and efficiency, should be used.

Presented in this paper is a model that addresses the topic of this special issue: Risk Analysis Validation and Trust in Environmental Risk Management. We do that by presenting a systems approach that links all four of those concepts. [9] The underlying logic: Validation should test how effectively a risk analysis supports actual, real-world implemented risk management. Our approach is based on a flowchart linking all of the elements from inputs through risk analysis, risk reporting and transparency, then how that reporting-transparency support the risk management decision making process and associated third party and stakeholder reviews (formal or informal), which in turn determine the trust and acceptance necessary for the real-world implementation of risk management actions.

We take that flowchart and identify within it sixteen critical elements. Then, we specify a validation test for each of those elements. Validation, then, consists of subjecting the risk analysis to those sixteen tests. Those tests, taken together, assess the effectiveness of the risk analysis for supporting implemented risk management. Another key feature: We divide the flowchart into an Analysts' Domain, a Users' Domain, and an Analysis Community Domain. The Analysts' Domain is where the risk analysts work; then, the Users' Domain stands between their work and implementation. The Analysis Community Domain is comprised of the communities of risk analysts and commissioners of risk analyses. Those two communities are where we would, as part of building our systems approach to risk analysis validation, build a "Culture of Analysis Quality," where the sixteen validation tests would be enforced by both of those communities [3-8, 14, 15, 19].

Consider a mechanism that regulates the reduction of deviations from product quality and, at the same time, contributes to savings of current costs and to minimizing risks. According to the economic model under consideration, all costs are divided into managed and control costs. Managed costs (losses, unforeseen costs) are the costs of eliminating defects and defects in the production process caused by nonconformities, as well as the elimination of defects identified after production. Management costs (costs of quality 
management) - the costs of preventing and identifying non-conformances using quality assessment methods.

Consider the classification of costs associated with the quality of products (Fig. 1). It can be seen from the figure that the control costs (the cost of quality management) should influence the cause of the losses.

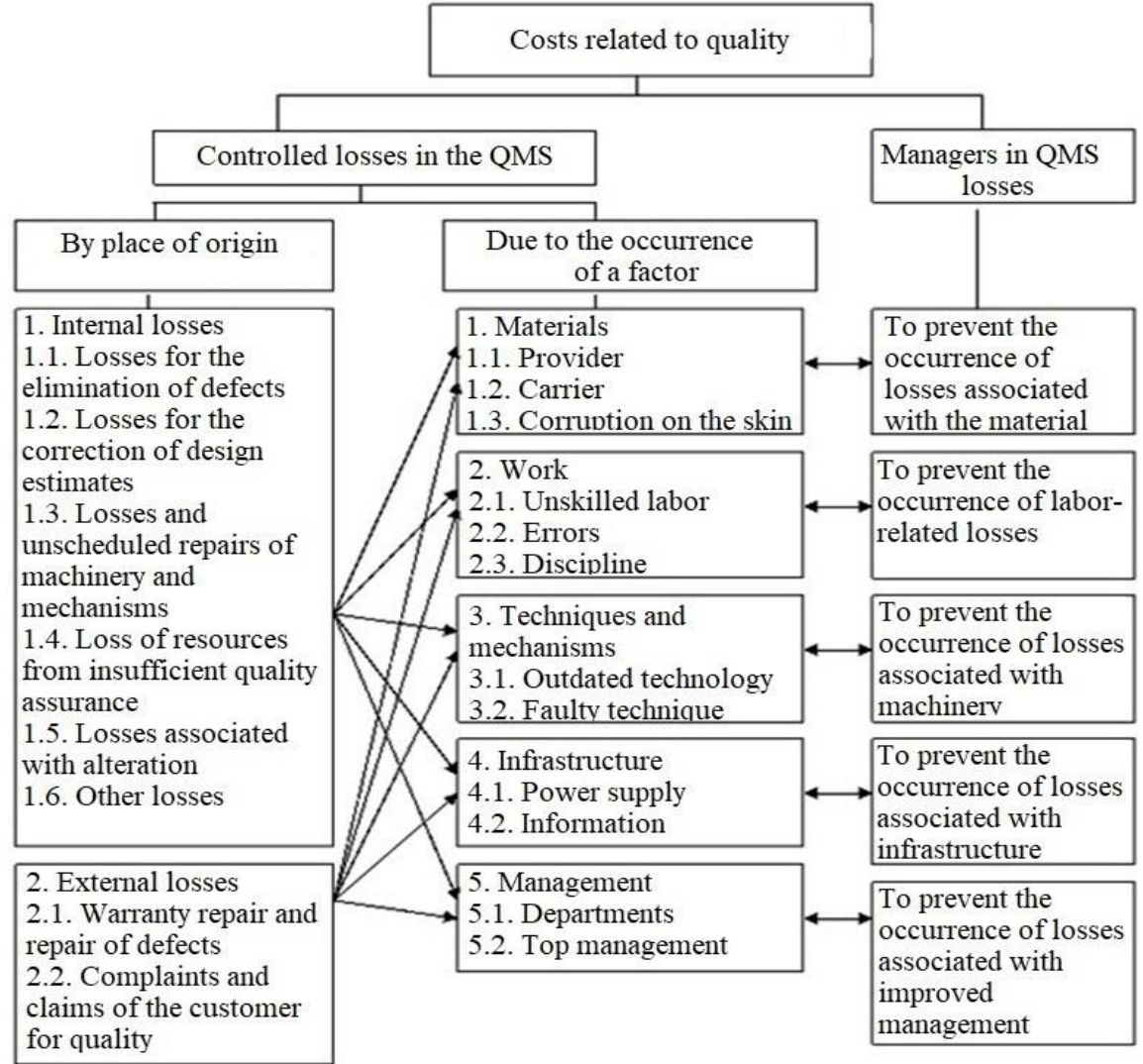

Fig. 1. Classification of costs associated with the quality of products and the relationship of the main elements.

Let us consider in detail what managers can invest in QMS. The costs of preventive actions include costs:

- Development of QMS documentation;

- Legal support of the quality management system (acquisition of legislative regulations, legal examination of documents related to quality assurance, certification of the quality system);

- Information support (development of accounting methods and forms of registration of quality data, purchase of information equipment, organization of collection of quality information, processing, storage, analysis of quality information);

- Personnel training (defining the qualifications of employees, developing training programs for employees in the field of quality); and

- Accounting for costs of quality assurance (development of documentation for assessing costs).

Reduction of environmental losses, by the elimination of defective products, and rejects in the production process lead to a significant economic effects. The amount of management costs is determined by the management of the organization and depends on the cost of 
implementing the quality system and the cost of the quality assessment. With the decrease in losses from machinery, the effectiveness of managers in the QMS for investments and investments increase. The environmental economic model for managing costs and risks, as an instrument of rational use of financial resources, is able to optimize the costs of quality assurance for products and services with maximum efficiency [12].

Organizational capabilities in companies, within IT settings, can be strengthened by a centralized and integrated risk management approach based on ISO standards. This paper analyses risk management activities throughout various selected ISO standards in order to provide the basis to improve, coordinate and interoperate risk management activities in IT settings for various purposes related to quality management, project management, IT service management and information security management. Taking as a basis the ISO 31000 international standard for risk management, a comparison is performed with the aim of identifying risk management related activities in the ISO high level structure for management system standards, ISO 9001, ISO 21500, ISO/IEC 20000-1 and ISO/IEC 27001. These standards are of high interest for practitioners in IT settings, benefitting from the integration of process-based activities, implementing mechanisms for linking IT and non-IT entities of their organization with risk management challenges to address. Integration vectors such as the understanding of the organisation and its context, risk-based thinking, leadership and commitment, process approach and PDCA structure are elicited [12, 13, 16-18].

\section{Materials and methods}

The environmental economic model of cost management and environmental risk management is valid for any organization. In this article, the functioning of the economic model is considered using the example of construction industry organizations. The main condition of the model is the developed and implemented quality management system, which facilitates rapid and rapid control of processes and associated costs and risks. The effective functioning of the QMS and the economic model of managing costs and risks is ensured by the use of a systemic and process approach [12].

First of all, management activity is a cyclic order of performing interrelated practical actions, known as the Deming-Shewhart cycle (Fig. 2).

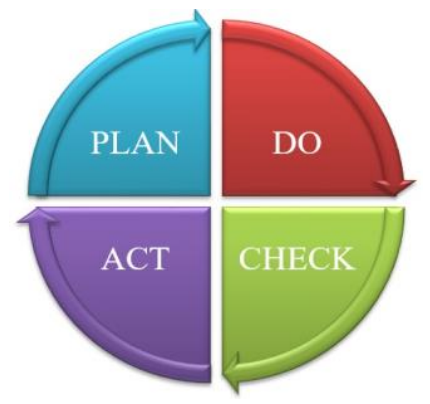

Fig. 2. Scheme of the Edward Deming (PDCA cycle).

The content of the cycle includes a set of procedures, divided into several stages: PlanDo-Check-Act (a PDCA cycle). After the last stage, a new cycle of the same practical actions should be started at the same workplaces, but with new goals and objectives to reduce risks. And, secondly, the implementation of the same cyclic procedures performs a "technological approach" in solving problems that allow providing conditions for continuous improvement of working conditions, continuous improvement of the OSH management system $[1,2]$. 
Control is possible only for those processes that have measurable or estimated parameters. In the field of eco-friendly construction and occupational safety, occupational hazards and hazards, expressed by quantitative or qualitative parameters of occupational risk, are taken as such parameters. Risk management means the recognition and analysis of risks, the development and implementation of management decisions to reduce the likelihood of adverse situations, as well as the possible reduction of material or other losses. Risk management helps to get out of the zone of uncertainty into a situation with more or less predictable results $[3,12]$.

Risks are created by the dangers and harmfulness of the process environment, as well as by the level and intensity of the workload of the personnel. It was formerly necessary to strive to create absolute security, to prevent any negative manifestations of the technological environment, but we must abandon the concept of zero risk, since all living conditions, especially in the field of material production, are accompanied by risky situations that cannot be avoided. Today, the concept of acceptable risk is used in practice, i.e., the level of risk that is recognized as acceptable by state bodies, the production community, public organizations, and directly by personnel $[4,8]$.

Risks are an objective phenomenon in the activity of the enterprise. They accompany all spheres of enterprise activity. Despite the fact that a number of risk parameters may depend on ambiguous actions of personnel or the adoption of subjective management decisions, the objective nature of its manifestation remains unchanged.

The very concept of risk means a combination of two factors, namely the probability of damage and the level of this damage. The higher the probability of material or other damage and the more expected losses, the higher the risk. At the same time, the risks may be the same in cases where there are situations, for example, with the maximum likelihood of the origin of the damage and the minimum indicators of its level. Or vice versa, in the case of a low probability of loss, while simultaneously waiting for significant damage [10].

\section{Results and Discussion}

The process approach allows us to divide the activities of the organization into processes through which the goals are achieved. This allows the analysis of customer requirements and ensures the manageability of the construction organization as a whole. The principle of the process approach allows the reduction of costs, effective use of available resources, and reduction of costs and duration of production cycles [2]. The application of the process approach leads to a clear definition of responsibility for all existing processes, orientation on factors (test methods, resources, materials) that contribute to the improvement and efficiency of the company's operations.

The activities of the construction company in general terms can be represented as a process (Fig. 3), described using the IDEF0 methodology. 


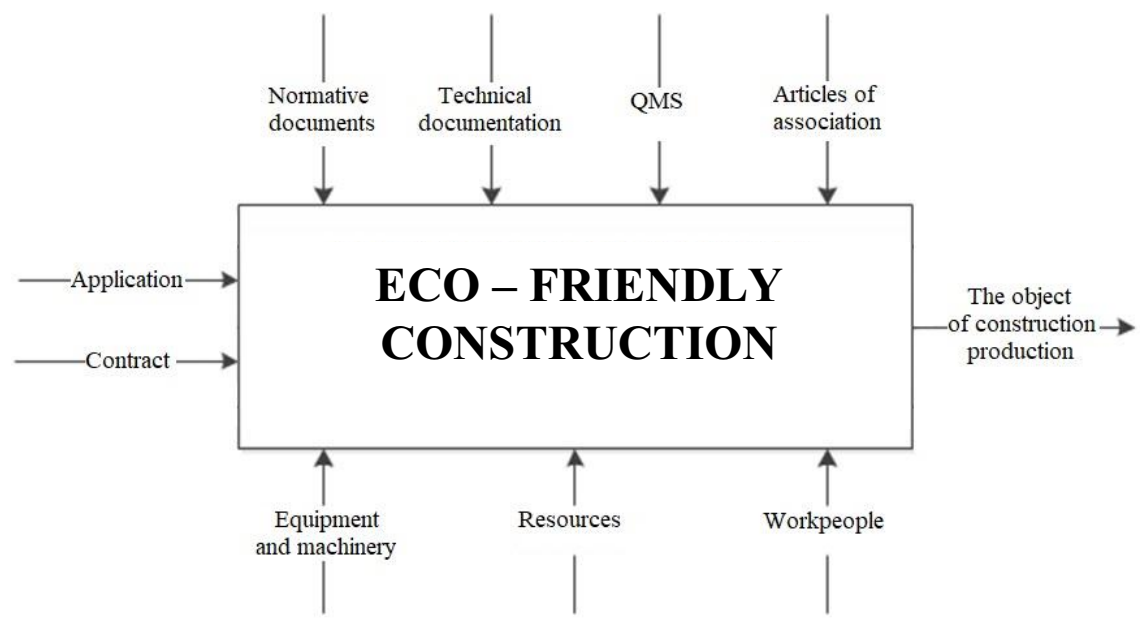

Fig. 3. The process of eco-friendly construction in accordance with the methodology IDEF0.

This methodology defines the inputs, outputs, information and resources needed for the process. The construction of the testing laboratory processes is implemented as a PDCA cycle (Fig. 4).

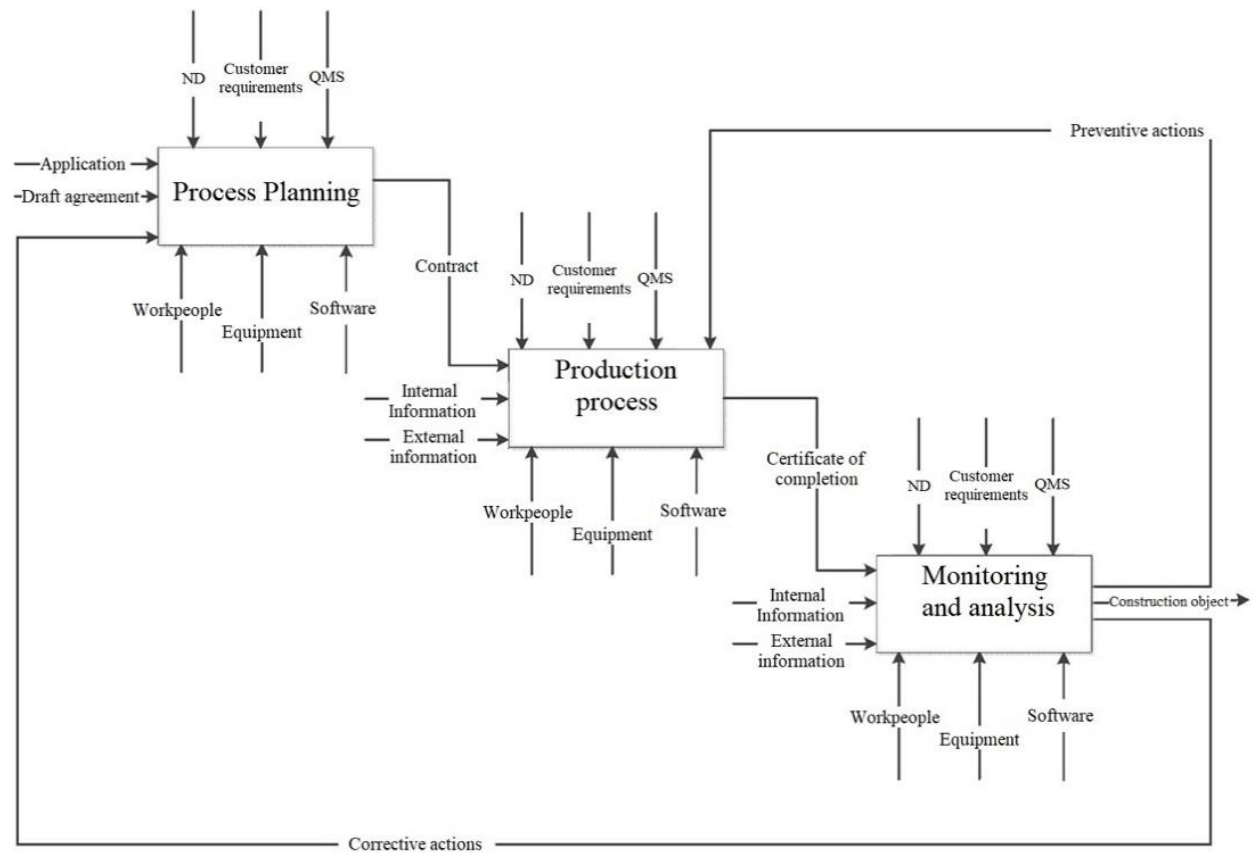

Fig. 4. The process of eco-friendly construction in accordance with the PDCA cycle.

According to the PDCA model $[3,4]$, in the construction organization, when the process approach is implemented, the process is continuously improved, resulting in improved activities and, most importantly, consumer confidence. According to the PDCA cycle used in building the processes, "Planning" allows evaluation and planning of the desired result. In "Implementation," planned activities are implemented and results are evaluated. "Verification" involves analyzing the results and allows you to draw conclusions. At the stage of "Management", actions based on conclusions are made. If successful results are achieved 
in the previous stages, this experience will be used in future activities. And if not, then the applied cycle will be repeated again, until the planned results are achieved. Such approach allows finding and defining points of process control, to clearly understand the essence of the process approach in the organization, and to identify direct and indirect risks.

Further decomposition of the organization's processes determines the stages of development and functioning of the process (Fig. 5).

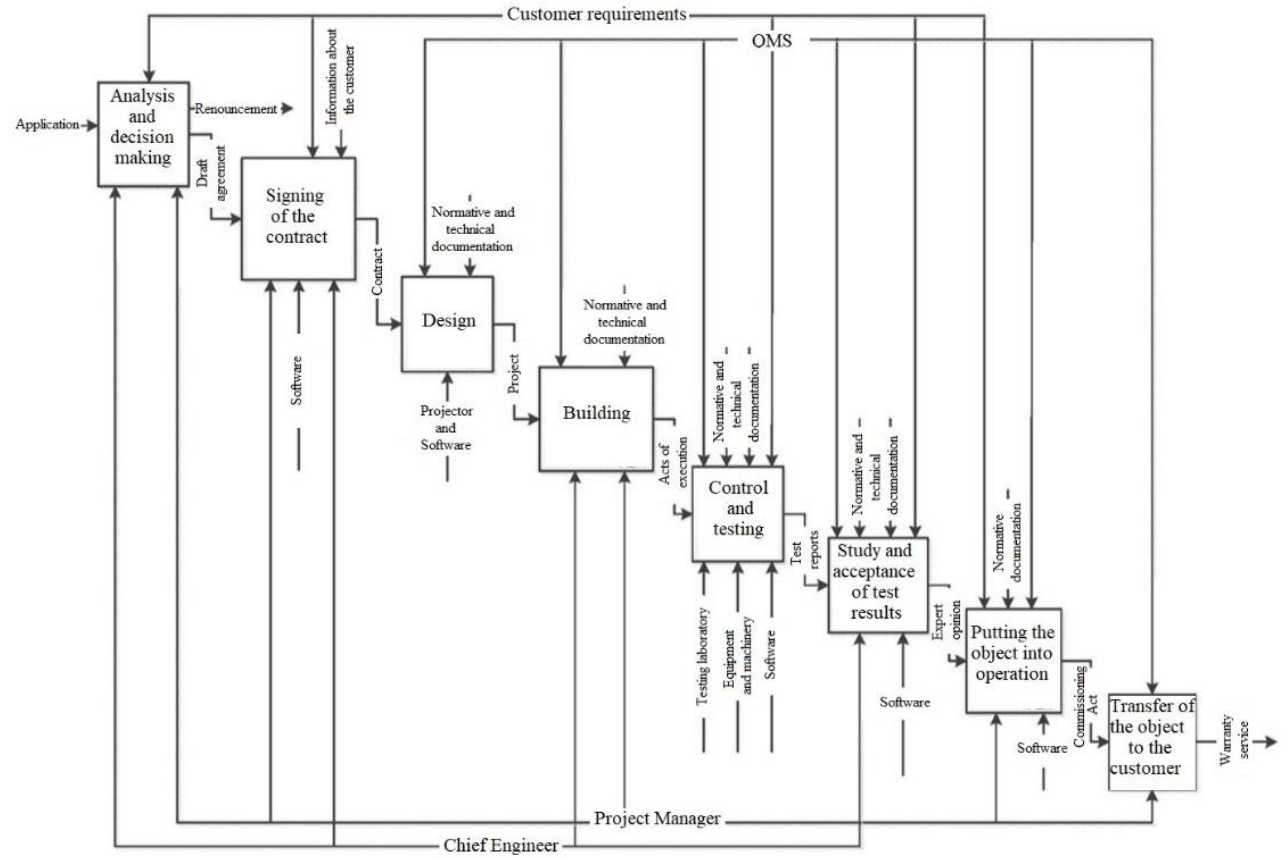

Fig. 5. Decomposition of the eco-friendly construction process in accordance with the PDCA cycle.

The application of the systems approach allows the realization in the economic model of the costs and risk management in the organization through previously identified direct and indirect risks and costs associated with them.

The introduction of the process approach is one of the most important factors determining the QMS as a workable and efficient system. Simplicity of the description of processes allows at any question concerning activity of laboratory. At each stage, the responsible and the requirements for the process must be defined, which allows systemization of the organization's activity, prompt reaction to any changes, and tracking of any inconsistencies at the stage of occurrence, with the subsequent exclusion from the process.

\section{Conclusions}

The considered environmental economic-management model promotes prompt reaction to any changes in the field of eco-friendly construction and occupational safety, in which it is customary to allocate occupational hazards and hazards expressed by quantitative or qualitative parameters. Environmental risk management for the model considered means the recognition and analysis of risks, the development and implementation of management decisions to reduce the likelihood of adverse situations, as well as the possible reduction of material or other losses. Integrated risk and cost management mechanisms help to exit the zone of uncertainty into a situation with more or less predictable results. 
Synthesis of the principles of the quality management system and mechanisms for managing environmental risks and costs ensures high adaptability to any external and internal stress situations, timely reveals professional risks, optimizes processes and, as a result, reduces costs. Analysis of technical and accounting documentation of construction organizations has revealed the need, in an ever-changing market environment, to use integrated environmental economic and management models.

\section{References}

1. M. Lazarevska, M. Knežević, M. Cvetkovska, N. Ivanišević, T. Samardžioska, A. Trombeva-Gavriloska, Gradjevinar 7/2012(64), 565-571 (2012) ISSN (on line): 13339095; ISSN (printed) 0350-2465

2. Sun Tsu, The Art of War (Sunzi Bingfa, Giles Translation), Ch 8. The Internet Classics Archive by Daniel C. Stevenson, Web Atomics. World Wide Web presentation, citing classics@classics.mit.edu

3. V.G. Borkovskaya, Applied Mechanics and Materials. Engineering Management 475476(15), 1703-1706 (2013) DOI: 10.4028/www.scientific.net/AMM.475-476.1703

4. H. Skipper, J. Kwon, Risk Management and Insurance, Perspectives in a Global Economy (Wiley, 2007)

5. D. Kahneman, A. Tversky, Econometrica 47(2), 263-291 (1979)

6. An. Mottaeva, Oil, gas and business 5, 22-28 (2011)

7. An. Mottaeva, V. Lukinov, As. Mottaeva, Economy and entrepreneurship 8 (49), 34-37 (2014)

8. V.G. Borkovskaya, Materials Science and Mechanical Engineering. Chapter 2: Building Materials and Construction Technologies 1, 287-290 (2013) DOI: 10.4028/www.scientific.net/AMM.467. 287

9. R.K. Sawyer, The Cambridge Handbook of the Learning Sciences (Cambridge University Press, Cambridge, 2006)

10. V.G. Borkovskaya, Advanced Materials Research. Engineering Education 860-863(26), 3009-3012 (2013) DOI: 10.4028/www.scientific.net/AMR.860 -863.3009

11. E. Chibisova, Journal of International Scientific Publications: Economy \& Business 52, 600 (2015)

12. V.G. Borkovskaya, Manufacturing Management and Engineering Management 945949, 3012-3015 (2014) DOI: 10.4028/www.scientific.net/AMR.945-949.3012

13. B. Bloom, Taxonomy of Educational Objectives (Cognitive Domain, 1956)

14. D. Bandaly, L. Shanker, Y. Kahyaoglu, A. Satir, Risk Management 15(1), 1-31 (2013)

15. Y. Lin, R. D. MacMinn, R. Tian, J. Yu, Journal of Risk and Insurance 84(S1), 345-365 (2017)

16. D. Passmore, R.M. Baker, Sampling strategies and power analysis. Research in organizations: Foundations and methods of inquiry (Berrett-Koehler, San Francisco, 2005)

17. S. Stranieri, L. Orsi, A. Banterle, Supply Chain Management 22(2), 145-159 (2017) DOI: 10.1108/SCM-07-2016-0268

18. B. Barafort, M. Antoni-Lluís, A. Mas, Computer Standards \& Interfaces 54(3), 176-185 (2017) ISSN 0920-5489, DOI:10.1016/j.csi.2016.11.010 
19. J. Lathrop, B. Ezell, Safety Science 99(B), 187-195 (2017) ISSN 0925-7535, DOI: 10.1016/j.ssci.2017.04.006 